\title{
In silico study of Ayapana triplinervis, Bioactive, Compounds against Quorum-Sensing System of Pseudomonas aeruginosa
}

\author{
KING DAVE GLORIA MARTIN, ${ }^{1}$ KRYSTEL GRACE VERGARA PADILLA ${ }^{1 *}$ \\ and IVY JOYCE ARENAS BUAN ${ }^{1}$
}
${ }^{1}$ Chemistry and Environmental Science Department, College of Arts and Sciences, Nueva Ecija University of Science and Technology, Cabanatuan City, Nueva Ecija, 3100, Philippines.
${ }^{*}$ Corresponding author E-mail: krystelgrace_vergara@yahoo.com

http://dx.doi.org/10.13005/ojc/370119

(Received: January 22, 2021; Accepted: February 23, 2021)

\begin{abstract}
Quorum sensing is the way bacterial cells communicate can trigger or regulate pathogenicity in Pseudomonas aeruginosa. Targeting the quorum sensing system with the help of docking algorithms can reduce the cost and time to screen for potential anti-quorum sensing drugs. Ayapana triplinervis, an ethnobotanical from the Philippines is a potential source of bioactive compounds to inhibit quorum sensing. This study shows potential compounds present in Ayapana triplinervis that could disrupt the quorum sensing system in Pseudomonas aeruginosa with the use of molecular docking simulations. Selection and identification of bioactive compounds found in Ayapana triplinervis was based from previous metabolite screening reports. This study utilizes virtual screening in order to identify which among the compounds to be the potent quorum sensing inhibitor. The molecular structures of the thirtyone identified bioactive compounds were obtained from PubChem (nih.gov) in SDF file. These molecular structures of the compounds from Ayapana triplinervis served as the ligands and docked to the active site of the PqsR, PqsD, and LasR of the Pseudomonas aeruginosa using Autodock Vina algorithms. The bioactive compounds were virtually screened using Autodock Vina to determine the binding affinity of each compounds to the active site of PqsR, PqsD, and LasR. Compounds with a low binding affinity has a potential to be developed as anti-quorum agent to Pseudomonas aeruginosa. Results showed that out of the 31 compounds, caryophyllene, trans-nerolidol, 2-(Isobutyryloxy)-Thymol methyl ether, $\beta$-elemene and cyperadiene have successfully inhibited the PqsR, PqsD, and LasR based from the computed binding affinity. 2-(Isobutyryloxy)-Thymol methyl ether formed hydrogen bond in the active site of all the proteins related governing the quorum sensing process of Pseudomonas aeruginosa, making the compound a candidate drug to disrupt the signaling pathway of the system.
\end{abstract}

Keywords: Quorum sensing, Ayapana triplinervis, Pseudomonas aeruginosa, Molecular Docking, Autodock Vina.

\section{INTRODUCTION}

The world annual death toll due to the development of antibiotic resistance in bacteria is estimated to have reached 700000 , and it is expected that it would upsurge to 10 million deaths annually by $2050^{1}$. Due to mismanagement and abuse in the prevailing antibiotics in animals, humans

This is an Open Access article licensed under a Creative Commons license: Attribution 4.0 International (CC- BY). Published by Oriental Scientific Publishing Company @ 2018

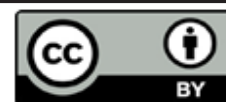


and plants, there is an emerging development of antimicrobial resistant pathogenic strains of bacteria ${ }^{2}$. Besides, Durao et al., ${ }^{3}$ reported that the conventional antibiotics target bacteria's vital processes leading to development arrest, creating a selective pressure leading to more multi-drug resistant modifications. In future, the issue with antibiotic resistance will be a problem in the health sector based on the World Bank's assessment and will cause a decrease in the gross domestic manufacture in 2050 that would be analogous to the global economic devastation last 2008-20094.

Pseudomonas aeruginosa, a ubiquitous, opportunistic Gram-negative bacterium ${ }^{5}$ is capable of forming biofilms on number of living and nonliving surfaces. It can form biofilms in the airways of individuals affected by cystic fibrosis (CF) $)^{6,7}$. To control this microbial assault, CF individuals are treated with high-dose antibiotic therapies. $P$. aeruginosa can exploit the altered environment within the CF lung to become the dominant infecting agent in CF adolescents and adults ${ }^{8}$. Over time, colonizing $P$. aeruginosa transition from a highly virulent lifestyle to a less cytotoxic, biofilm mode of growth, characterized by overproduction of the exopolysaccharide alginate. This state is often described as mucoidy ${ }^{9}$.

Pseudomonas aeruginosa uses three different quorum sensing apparatus including Luxl/R-type systems (Lasl/R and Rhll/R) and PQS (Pseudomonas quinolone signal). LasR is an important regulator for the expression of genes like aprA, lasA, and toxA that control virulence factor expression ${ }^{10}$. On the other hand, Pseudomonas quinolone signal (PQS) system, also regulates quorum sensing through PqsR by promoting the transcription of genes involved in the quorum sensing process $^{11}$.

Considering the threats that the quorum sensing imposes to the society, there is a need in finding a solution for preventing quorum sensing. As mentioned, quorum sensing is under the control of Luxl/R-type systems and PQS and targeting key proteins in the quorum sensing system is a possible answer in addressing the issue specifically with the use of anti-QS compounds. Disruption of autoinducers-receptor binding could interfere with the system, thus preventing the expression of genes for biofilm formation ${ }^{12}$. Anti-quorum sensing does not place selective pressure on the growth of bacteria, thus development of resistance is unlikely to occur ${ }^{13}$. With this, there is an increasing attention in the discovery of anti-QS compounds especially in natural products research ${ }^{12}$.

One potential source of bioactive compounds are ethnobotanicals. Ayapana triplinervis, also known as Eupatorium triplinerve Vahl, is listed as one of the ethnomedicinal plants in the Philippines ${ }^{14}$ and is broadly used in traditional medicine for wound treatment and bloating ${ }^{15}$, stomachic illness, antiulcerous and to fight cough ${ }^{16}$. In addition, the plant extract is also utilized as a sedative, anxiolytic, and antidepressive ${ }^{17}$. Ethnomedicinal studies show that Ayapana triplinervis are widely used in countries like Brazil, India, Sri Lanka, Bangladesh, Mauritius, West Indies, Peru, and Europe for medicinal purposes ${ }^{18}$. Some of the reported antibacterial activity of the A. triplinervis extracts are against Streptococcus pyrogens and Pseudomonas aeruginosa ${ }^{19}$, Staphylococcus aureus ${ }^{20}$, Escherichia coli and Enterococcus faecalis ${ }^{21}$. Screening of phytochemicals in the hydroalcoholic extract in the different parts of $A$. triplinervis revealed that steroids, coumarins, alkaloids, saponins, tannins, and depsides are present in the plant ${ }^{21}$. The occurrence of the mentioned phytochemicals in $A$. triplinervis could be the reason for the quorum sensing activity against $P$. aeruginosa's swarming and pyocyanin production $^{22}$. Moreover, additional studies show that A. triplinervis has an anti-quorum sensing activity against $S$. aureus's alpha-hemolysin ${ }^{14}$, DNAse, and tube coagulase virulence production ${ }^{23}$.

Nowadays, researches related to computerbased simulation of ligand-receptor binding for drug discovery is a cost-effective way of screening metabolically active compounds ${ }^{24}$. Molecular docking studies plays a significant role in the process of drug discovery as it shows the interaction of molecules with the active site of target protein at the atomic level ${ }^{25}$. The method helps in selecting biochemically active molecules thereby preventing late-stage clinical failures.

In this study, screening of bioactive compounds from Ayapana plant as quorum sensing inhibitor of Pseudomonas aeruginosa was done using Autodock Vina. Targeted proteins used to 
theoretically stop quorum sensing were LASR1, PqsR, and PqsD.

\section{MATERIALS AND METHODS}

\section{Protein and Ligand Preparation}

Crystal structures of PqsR, LasR, and PqsD were retrieved from Protein Data Bank with PDB ID: 4Jvi, 2uv0 and 3h76 (https://www.rcsb.org/). The structures of PqsR, LasR, and PqsD were obtained in X-ray crystals and refined at the resolutions of $2.5 \AA$ for PqsR, $1.82 \AA$ A for LasR and 2.8 A for PqsD. The active site of PqsR was identified according to the study of Ilangovan et al., ${ }^{26}$ and the active site for LasR was selected based on the study of Bottomley et al., ${ }^{27} \mathrm{PqsD}$ 's active site was identified based from the study of Bera et al., ${ }^{28}$.

Table 1: Active site of PqsR, Lasr and PqsD

\begin{tabular}{lccccccc}
\hline Proteins & \multicolumn{7}{c}{ Amino Acids in the Active Site } \\
\hline PqsR & Ala 102 & Pro 129 & Ile 149 & Ala 168 & Val 170 & Ile 186 \\
& Ala 187 & Leu 189 & Ala 190 & Leu 197 & Leu 207 & Leu 208 \\
& Arg 209 & & & & & \\
LasR & Tyr 56 & Trp 60 & Arg 61 & Asp 73 & Thr 75 & Ser 129 \\
PqsD & Leu 81 & Cys 112 & Leu 155 & Phe 218 & Met 220 & Met 225 \\
& His 257 & Pro 259 & Asn 287 & & & \\
\hline
\end{tabular}

The non-amino acids in the PqsR, LasR, and PqsD were removed using Swiss-Pdb viewer then saved to pdb file. Selection and identification of bioactive compounds found in Ayapana triplinervis were identified according to the metabolite screening study conducted by Gauvin-Bialecki and Marodon 29 . A total of 31 bioactive compounds were found to be present in Ayapana triplinervis, the molecular structures of the 31 compounds were obtained from PubChem (nih.gov) in SDF file as shown in Table 2. These molecular compounds served as the ligands to inhibit the active site of the PqsR, LasR, and PqsD. The obtained ligands were then clustered using BIOVIA Discovery Studio Visualizer-2020 and saved as MDL/MOL SD file that would be further needed for the molecular docking simulation.

\section{Molecular Docking}

The active site-directed docking was performed in Pyrx software with Autodock Vina using a Lamarckian Genetic Algorithm scoring function ${ }^{30,31}$. The 4Jvi, 2uv0, and $3 \mathrm{~h} 76$ and the ligand cluster was imported to the Pyrx. The ligand clusters were minimized and converted to autodockligand pbqt file. The docking site was set to a grid box of 26 . 9032 A x $23.5713 \times 17.4168$ for Pqsr, $19.5899 \times$ $14.0834 \times 11.7517$ for LasR and 22.7562 x $21.8527 \times$
15.6389 for PqsD. The binding affinity $(\mathrm{kcal} / \mathrm{mol})$ was obtained and specifies that the ligand binds to the target amino acids present in the active site of the quorum sensing apparatus of $P$. aeruginosa.

Table 2: Bioactive compounds in Ayapana triplinervis

\begin{tabular}{|c|c|c|}
\hline Compounds & $\mathrm{MW}(\mathrm{g} / \mathrm{mol})$ & PubChem ID \\
\hline Methyl salicylate & 152.15 & 4133 \\
\hline$\alpha$-pinene & 136.23 & 6654 \\
\hline Thymol & 150.22 & 6989 \\
\hline$\alpha$-phellandrene & 136.23 & 7460 \\
\hline Terpinine & 136.23 & 7461 \\
\hline p-Cymene & 134.22 & 7463 \\
\hline Thymoquinone & 164.2 & 10281 \\
\hline$\beta$-phellandrene & 136.23 & 11142 \\
\hline 2-(4-methylphenyl)propan-2- ol & 150.22 & 14529 \\
\hline$\alpha$-terpineol & 154.25 & 17100 \\
\hline Limonene & 136.23 & 22311 \\
\hline trans-Piperitol & 154.25 & 85568 \\
\hline 4,8-Dimethylnona-1,3,7- triene & 150.26 & 103555 \\
\hline cis-p-Menth-2-en-1-ol & 154.25 & 122484 \\
\hline$\beta$-pinene & 136.23 & 440967 \\
\hline$\beta$-Selinene & 204.35 & 442393 \\
\hline Neryl acetate & 196.29 & 1549025 \\
\hline Caryophyllene & 204.35 & 5281515 \\
\hline$\beta$-Ocimene & 136.23 & 5281553 \\
\hline Trans-Nerolidol & 222.37 & 5284507 \\
\hline $\begin{array}{l}\text { 2-(Isobutyryloxy)-Thymol } \\
\text { methyl ether }\end{array}$ & 250.33 & 6429186 \\
\hline Drima-7,9(11)-diene & 204.35 & 6429215 \\
\hline Selin-11-en-4-a-ol & 222.37 & 6429281 \\
\hline$\beta$-elemene & 204.35 & 6918391 \\
\hline$\alpha$-selinene & 204.35 & 10856614 \\
\hline Trans-pinocarvyl acetate & 194.27 & 12858461 \\
\hline cis- $\beta$-Elemene & 206.37 & 91750185 \\
\hline Cyperadiene & 202.33 & 91750187 \\
\hline$\alpha$-thujene & 136.23 & 162224174 \\
\hline trans-p-Menth-2-en-1-ol & 154.25 & 273941693 \\
\hline Isopatchoula-3,5-diene & 202.34 & 274426986 \\
\hline
\end{tabular}

\section{Protein-ligand Interaction}

The protein-ligand complex file from Pyrx was imported to Pymol to export as a pdb file. The intermolecular bonds formed in the protein-ligand interaction was identified in the BIOVIA Discovery Studio visualizer-2020.

\section{RESULTS AND DISCUSSION}

Molecular docking method generates the binding affinity values which denotes the strength of association between two molecules. The negative value correlates the spontaneity of the reaction between the molecule and active site of the targeted protein due to the disruption of total intermolecular and torsional energies. A previous report related to metabolite screening of Ayapana triplinervis conducted by Bialecki and Marodon have 
successfully identified the bioactive compounds present in the plant ${ }^{29}$. From the mentioned study, thirtyone compounds present in Ayapana triplinervis were selected to serve as the ligands, molecular structures of the compounds were obtained from from PubChem (nih. gov) in SDF file. Molecular docking simulation utilizing Lamarckian Genetic Algorithm scoring function shows that the selected metabolites have successfully made an interaction to the active site of $P$. aeruginosa's LasR, $\mathrm{PqsR}$, and PqsD based from the generated binding affinity values. Table 3 shows the binding affinity of the 31 bioactive components of Ayapana to the active site of the mentioned quorum sensing related proteins. Isopatchoula-3,5-diene exhibited the lowest binding affinity to PqsR with a value of -7.8 while $\alpha$-selinene was found to be the best inhibitor against LasR with binding affinity value of -9.6. Lastly, trans-nerolidol showed the lowest binding affinity to PqsD with a value of -6.3 .

Table 3: Binding affinity of bioactive components of Ayapana triplinervis to LasR, PqsR and PqsD

\begin{tabular}{|c|c|c|c|}
\hline \multicolumn{4}{|c|}{ Binding Affinity (kcal/mol) against } \\
\hline $\begin{array}{l}\text { Ayapana triplinervis } \\
\text { Bioactive Compounds }\end{array}$ & PqsR & LasR & $\mathrm{PqsD}$ \\
\hline Methyl salicylate & -5.9 & -7.4 & -5.5 \\
\hline$\alpha$-pinene & -6.3 & -6.8 & -5.1 \\
\hline Thymol & -6.3 & -6.8 & -5.1 \\
\hline$\alpha$-phellandrene & -6.1 & -7.2 & -5.2 \\
\hline Terpinine & -6.1 & -7.4 & -5.1 \\
\hline p-Cymene & -6.1 & -7.4 & -5.1 \\
\hline Thymoquinone & -6.1 & -8.4 & -5.4 \\
\hline$\beta$-phellandrene & -6.3 & -7.1 & -5.2 \\
\hline 2-(4-methylphenyl)propan- 2-ol & -6 & -7.7 & -5.5 \\
\hline$\alpha$-terpineol & -6.1 & -7.2 & -5.3 \\
\hline Limonene & -6.1 & -7.1 & -4.9 \\
\hline trans-Piperitol & -6 & -7.4 & -4.9 \\
\hline $\begin{array}{l}\text { 4,8-Dimethylnona- } \\
\text { 1,3,7-triene }\end{array}$ & -6.2 & -6.8 & -5.5 \\
\hline cis-p-Menth-2-en-1-ol & -6.2 & -7.2 & -4.4 \\
\hline$\beta$-pinene & -6.4 & -6.7 & -4.4 \\
\hline$\beta$-Selinene & -7 & -8.6 & -4.4 \\
\hline Neryl acetate & -6.2 & -7.6 & -5.8 \\
\hline Caryophyllene & -7.7 & -7.6 & -5.3 \\
\hline$\beta$-Ocimene & -6.2 & -6.9 & -5.3 \\
\hline Trans-Nerolidol & -6.7 & -8.4 & -6.3 \\
\hline 2-(Isobutyryloxy)- & -6.3 & -7.5 & -5.4 \\
\hline Thymol methyl ether & & & \\
\hline Drima-7,9(11)-diene & -7.3 & -6.2 & -4.3 \\
\hline Selin-11-en-4-a-ol & -6.9 & -8.6 & -3.8 \\
\hline$\beta$-elemene & -6.4 & -7.8 & -5.5 \\
\hline$\alpha$-selinene & -7 & -9.6 & -4 \\
\hline Trans-pinocarvylacetate & -6.5 & -8 & -4 \\
\hline cis- $\beta$-Elemene & -7 & -7 & -5.4 \\
\hline Cyperadiene & -7.4 & -6.8 & -0.8 \\
\hline$\alpha$-thujene & -6.3 & -6.8 & -5.4 \\
\hline trans-p-Menth-2-en-1-ol & -5.7 & -7.3 & -4.2 \\
\hline Isopatchoula-3,5- diene & -7.8 & -7.5 & -1.8 \\
\hline
\end{tabular}

Interaction of caryophyllene, transnerolidol, 2-(Isobutyryloxy)-Thymol methyl ether, $\beta$-elemene, and cyperadiene to the active site of PqsR, LasR, and Pqsd were identified and listed in Table 4. Selection of compounds was based on their binding affinity values to the selected proteins; the ligand should effectively bind to the active site of all the proteins. Hydrophobic Pi- alkyl and alkyl interaction between the ligands and receptor is the most common interaction in the three active sites.

2-(Isobutyryloxy)-Thymol methyl ether formed hydrogen bonds to PqsR, LasR and Pqsd, while trans-nerolidol only formed hydrogen bond to PqsR. Two-dimensional interactions of 2-(Isobutyryloxy)Thymol methyl ether to the active sites of PqsR, LasR, and Pqsd are shown in Fig. 1a-c. Interaction between 2-(Isobutyryloxy)-Thymol methyl ether and PqsR active site in Fig. 1.a shows that Leu A: 208 of the receptors formed a carbon bond with the ligand, while in LasR's active site in Fig. 1.b, 2-(Isobutyryloxy)-Thymol methyl ether generated an interaction with the protein's Ser E: 129. In the case of Pqsd, 2-(Isobutyryloxy)-Thymol methyl ether formed conventional hydrogen bond to Arg A: 262 and a carbon hydrogen bond to Asn A: 154 shown in Figure 1.c.

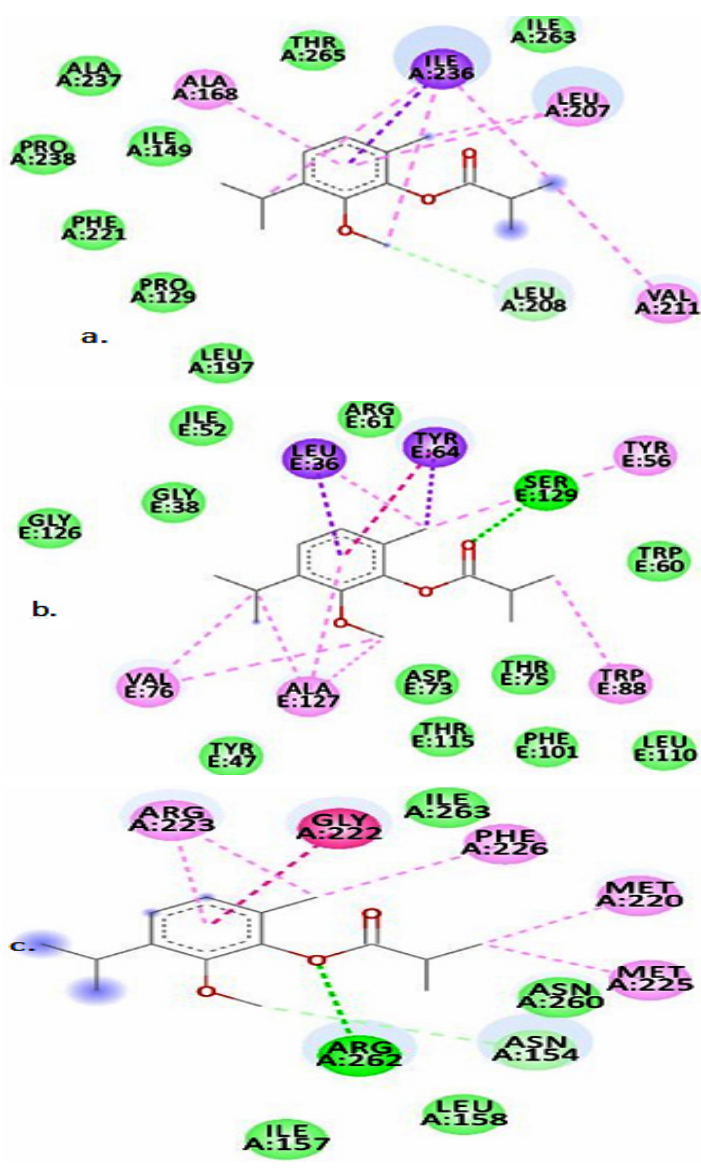

Fig. 1. Two-demensional Interaction of 2-(Isobutyryloxy)Thymol methyl ether with the active sites of PqsR (a), LasR (b), and PqsD (c) 
In order to combat infection due to $P$. aeruginosa's virulence factor, the use of anti- quorum sensing drug is a feasible way without the fear of developing antibiotic resistance (Mengjia Wang, 2020). P. aeruginosa utilizes 2-heptyl-3-hydroxy-4quinolone, also termed as Pseudomonas quinolone signal (PQS) and its precursor, 2-heptyl-4hydroxyquinoline (HHQ) for quorum sensing ${ }^{32}$. $P q s R$ is a transcriptional factor that responds to $P Q S$ and $H H Q$ for the stimulation of several virulence genes ${ }^{33}$. In a similar study conducted by Soukarieh and colleaugues ${ }^{34}$, result of in silico inhibition of PqsR shows that potential drugs for anti-quorum sensing create interaction to Tyr 258 ,
Leu 207, and Leu 208. This coincides with the result obtained from this study as the bioactive compounds obtained from Ayapana triplinervis showed inhibitory effect to the mentioned amino acid residues. In addition, Ile 236 interacted to caryophyllene, trans-nerolidol, 2-(Isobutyryloxy)Thymol methyl ether and $\beta$-elemene but not in cyperadiene. The difference in the interaction mode and affected amino acids present in the active site of $\mathrm{PqsR}$ is the reason for the difference in the docking energy of the bioactive compounds ${ }^{35}$. Interaction of the ligand to the active site deactivates the activity of PqsR by either making it inactive or preserving it as an unbound protein ${ }^{36}$.

Table 4: Summary of interaction formed between caryophyllene, trans-nerolidol, 2- (Isobutyryloxy)-Thymol methyl ether, $\beta$-elemene, and cyperadiene to Psuedomonas aeruginosa's PqsR, LasR, and Pqsd

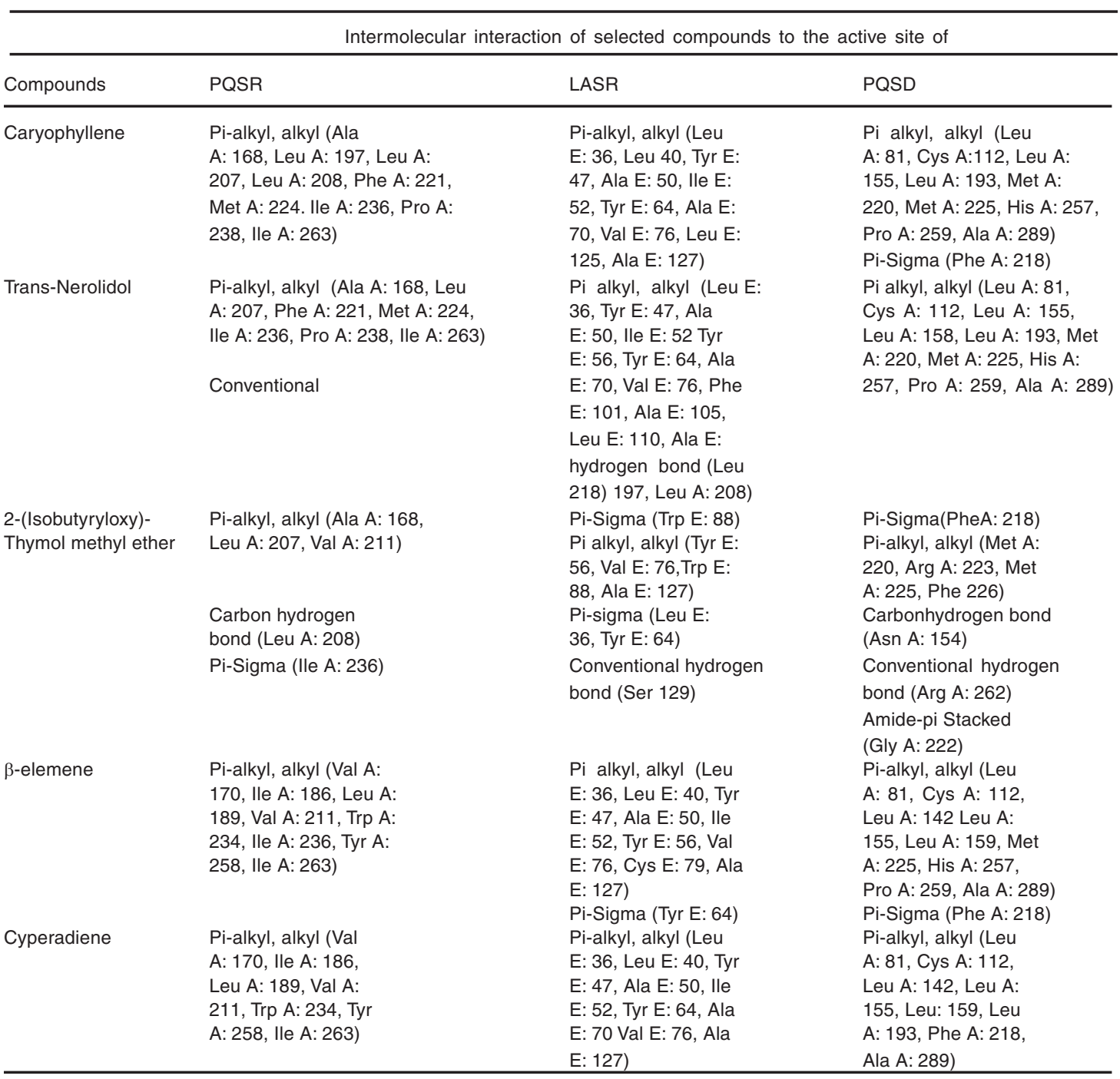


PQS and HHQ plays an important role in the cell to cell communication of $P$. aeruginosa. Synthesis of PQS includes anthranilate, which comes from either kynurenine pathway or from an anthranilate synthase $^{37}$. PqsD is an enzyme belonging to the $\beta$-ketoacyl- ACP synthase family which plays an important role in bacterial cell communication of $P$. aeruginosa as it catalyzes the final phase in the production of $\mathrm{HHQ}^{38}$. PqsD's catalytic triad consists of Cys 112, His 257, and Asn 287. Result from this study shows that caryophyllene, trans-nerolidol, $\beta$-elemene and cyperadiene interact with Cys 112, while caryophyllene, trans- nerolidol and $\beta$-elemene formed a bond with His 257. None of the listed compounds made an interaction with Asn 287. The function of Cys 112 is to make a nucleophilic attack to the thioester of anthraniloyl-COA $(\mathrm{ACOA})$ resulting to the subsequent elimination of $C O A$ and formation of anthranilate-PqsD complex ${ }^{39}$. Therefore, inhibition of amino acid residue Cys 112 also interrupts the catalytic activity of Pqsd.

LasR is composed of two autonomously folded domains, a ligand-binding domain (LBD) located at the $\mathrm{N}$-terminal end and a DNA-binding domain (DBD) that can be found at the $\mathrm{C}$ - terminal end of the protein. Interaction of $\mathrm{N}$-(3-Oxododecanoyl)L-homoserine lactone with the LasR's active site induces genes responsible for quorum sensing like lasl synthase leading to the production of $30 \mathrm{C} 12$ $\mathrm{HSL}^{40}$. In the active site of LasR, amino acids Trp 60, Tyr 56, Ser 129, and Asp 73 are important for the recognition of its native ligand ${ }^{41}$. Result from this study shows that trans-nerolidol, 2-(Isobutyryloxy)Thymol methyl ether and $\beta$-elemene formed hydrophobic interactions with Tyr 56. In addition, 2-(Isobutyryloxy)-Thymol methyl ether also formed a conventional bond with Ser 129. In this study, all of the selected compounds formed interactions to Ala 127. Thr75, Tyr 93, and Ala 127 are important amino acids in Las $R$ as it accommodates the binding of ligand in the active site of the selected protein ${ }^{42}$. All of the selected compounds made an interaction to highly conserved amino acids in LasR like Tyr64 and Val76. Binding of the selected compounds to the important and highly conserved amino acids of LasR suggests the possible competition in the active site of LasR ${ }^{43}$. Therefore, the inhibition of the mentioned amino acids interrupts the catalytic activity of LasR.

\section{CONCLUSION}

In conclusion, 31 bioactive compounds from Ayapana triplinervis were screened to become potential anti-quorum sensing inhibitors through inhibition of PqsR, PqsD, and LasR. Out of 31 compounds, caryophyllene, trans-nerolidol, 2-(Isobutyryloxy)-Thymol methyl ether, $\beta$ - elemene, and cyperadiene were able to generate low binding energy to all three selected proteins. Hydrophobic interaction dominated the ligand-receptor interaction in all compounds, while 2-(Isobutyryloxy)-Thymol methyl ether formed hydrogen bonding in all the selected proteins. Caryophyllene, trans-nerolidol, 2-(Isobutyryloxy)-Thymol methyl ether, $\beta$-elemene, and cyperadiene present in Ayapana triplinervis extracts were able to inhibit the activity of PqsR by forming a bond to Tyr 258, Leu 207, and Leu 208. PqsD was also inhibited by caryophyllene, transnerolidol, $\beta$-elemene and cyperadiene by forming hydrophobic interaction with amino acid residue Cys 112. In addition, LasR was also inhibited through competitive binding of ligands to the active site of LasR as shown by the interaction formed between Tyr 56, Ala 127, and Ser 129. With the results obtained from this study, it is recommended to further isolate and modify the bioactive compounds from Ayapana triplinervis for experimental studies.

\section{ACKNOWLEDGEMENT}

The authors are extending their heartfelt gratitude to the administration, faculty, and staff of the College of Arts and Sciences, Nueva Ecija University of Science and Technology for their support. Publication of this study was financially supported by the Nueva Ecija University of Science and Technology.

\section{Conflict of interest}

Authors of this study state that there is no conflict of interest in this study with regards to its publication. 


\section{REFERENCES}

1. Spaulding, C.N.; Klein, R.D.; Schreiber, H.L.; Janetka, J.W.; Hultgren, S. J. NPJ Biofilms Microbiomes., 2018, 4(1), 1-7.

2. Gupta, V.; Singhal, L. Springer: Singapore., 2018, 215-224.

3. Durão, P.; Balbontín, R.; Gordo, I. Trends Microbiol., 2018, 26, 677-691.

4. Padiyara, P.; Inoue, H.; Sprenger, M. J. Infect. Dis., 2018, 11, 1-4.

5. Trautmann, M.; Lepper, P. M.; Haller, M. American journal of infection control., 2005, 33(5), S41-S49.

6. Khan, W.; Bernier, S. P.; Kuchma, S. L.; Hammond, J. H.; Hasan, F.; O'Toole, G. A. International microbiology: The official journal of the Spanish Society for Microbiology., 2010, 13(4), 207.

7. Rau, M. H.; Hansen, S. K.; Johansen, H. K.; Thomsen, L. E.; Workman, C. T.; Nielsen, K. F.; Molin, S. Environmental microbiology., 2010, 12(6), 1643-1658.

8. Gangell, C.; Gard, S.; Douglas, T.; Park, J.; De Klerk, N., Keil, T.; Sly, P. D. Clinical infectious diseases., 2011, 53(5), 425-432.

9. Rowen, D. W.; Deretic, V. Moecular Microbiology., 2000, 36(2), 314-327.

10. Lee, J.; Zhang, L. Protein \& Cell., 2015, 6(1), 26-41.

11. Lu, C.; Kirsch, B.; Zimmer, C., De Jong, J. C.; Henn, C., Maurer, C. K.; ... Hartmann, R. W. Chemistry \& biology., 2012, 19(3), 381-390.

12. Packiavathy, I. A. S. V.; Priya, S.; Pandian, S. K.; Ravi, A. V. Food chemistry., 2014, 148, 453-460.

13. Koh, C. L.; Sam, C. K.; Yin, W. F.; Tan, L. Krishnan, T.; Chong, Y.; Chan, K. G. Sensors., 2013, 13(5), 6217-6228.

14. Padilla, K. G. V., Jacinto, W. R., Cruz, K. G. J. (2018). International Journal of Biology, Pharmacy and Allied Science., 2018, 7(8), 1537-1550.

15. Samoisy, A. K.; Mahomoodally, M. F. Journal of ethnopharmacology., 2015, 173, 20-38.

16. Begue, A.; Kowlessur, V.; Singh, U.; Mahomoodally, F.; \& Pudaruth, S. International Journal of Advanced Computer Science and
Applications., 2017, 8(4), 166-175.

17. Melo, A. S., Monteiro, M. C., da Silva, J. B., de Oliveira, F. R., Vieira, J. L. F., de Andrade, M. A., Maia, C.D.S. F. Journal of ethnopharmacology., 2013, 147(2), 293- 301.

18. Cheriyan, B. V.; Joshi, S.; Mohamed, S. Asian Journal of Pharmaceutical Research., 2019, 9(3), 200-202.

19. Krishnan, R. J.; Nair, S. R. American Journal of Plant Sciences., 2016, 7(6), 907-915.

20. Gupta, M.; Mazumder, U. K.; Chaudhuri, I.; Chaudhuri, R. K.; Bose, P.; Bhattacharya, S.; Patra, S. Fitoterapia., 2002, 73(2), 168-170.

21. Matos Lopes, T. R.; de Oliveira, F. R.; Malheiros, F. F.; de Andrade, M. A.; Monteiro, M. C.;Baetas Goncalves, A. C. Pharmaceutical Biology., 2015, 53(6), 897-903.

22. Padilla K. G. V.; Martin K.D.G. Orient. J. Chem., 2020, 36(5), 934-939.

23. Barrogo, K. N.; Jacinto, W. R.; Judan Cruz, K. G. International Journal of Biosciences., 2018, 13(4), 173-182

24. Buan, I. J. A.; Mendoza, D. V. M. Orient. J. Chem., 2020, 36(4), 767-772.

25. Meng, X. Y.; Zhang, H. X.; Mezei, M.; Cui, M. Current computer-aided drug design., 2011, 7(2), 146-157.

26. Ilangovan, A.; Fletcher, M.; Rampioni, G.; Pustelny, C.; Rumbaugh, K.; Heeb, S.; Williams, P. PLoS Pathog., 2013, 9(7), e1003508.

27. Bottomley, M. J.; Muraglia, E.; Bazzo, R.; Carfì, A. Journal of Biological Chemistry., 2007, 282(18), 13592-13600.

28. Bera, A. K.; Atanasova, V.; Robinson, H.; Eisenstein, E.; Coleman, J. P.; Pesci, E. C.; Parsons, J. F. Biochemistry., 2009, 48(36), 8644-8655.

29. Gauvin-Bialecki, A.; Marodon, C. Biochemical Systematics and Ecology., 2008, 36(11), 853-858.

30. Trott O. The Molecular Graphics Lab at The Scripps Research Institute - AutoDock Vina is an open-source program for doing molecular docking., 2010.

31. Dallakyan S.; Olson A. J. Methods Mol Biol., 2015, 1263, 243-50 
32. Yu, S.; Jensen, V.; Seeliger, J.; Feldmann, I.; Weber, S.; Schleicher, E.; Blankenfeldt, W. Biochemistry., 2009, 48(43), 10298-10307.

33. Lin, J.; Zhang, W.; Cheng, J.; Yang, X.; Zhu, K.; Wang, Y.; Shen, X. Nature communications., 2017, 8(1), 1-12.

34. Soukarieh, F.; Williams, P.; Stocks, M. J.; Camara, M. Journal of medicinal chemistry., 2018, 61(23), 10385-10402.

35. Wang, M.; Zhao, L.; Wu, H.; Zhao, C.; Gong, Q.; Yu, W. Marine drugs., 2020, 18(4), 205.

36. Boopathi, S.; Vashisth, R.; Manoharan, P.; Kandasamy, R.; Sivakumar, N. Bioorganic \& medicinal chemistry letters., 2017, 27(10), 2113-2118.

37. Bera, A. K.; Atanasova, V.; Robinson, H.; Eisenstein, E.; Coleman, J. P.; Pesci, E. C.; Parsons, J. F. Biochemistry., 2009, 48(36),
8644-8655.

38. Zhou, Z.; Ma, S. ChemMedChem., 2017, 12(6), 420-425.

39. Weidel, E.; de Jong, J. C.; Brengel, C.; Storz, M. P.; Braunshausen, A.; Negri, M.; Hartmann, R. W. Journal of medicinal chemistry., 2013, 56(15), 6146-6155.

40. O'Reilly, M. C.; Dong, S. H.; Rossi, F. M.; Karlen, K. M.; Kumar, R. S.; Nair, S. K.; Blackwell, H. E. Cell chemical biology., 2018, 25(9), 1128-1139.

41. Ahumedo, M.; Drosos, J. C.; Vivas-Reyes, R. Molecular bioSystems., 2014, 10(5), 1162- 1171.

42. Paczkowski, J. E.; McCready, A. R.; Cong, J. P.; Li, Z.; Jeffrey, P. D.; Smith, C. D.; Bassler, B. L. ACS chemical biology., 2019, 14(3), 378-389.

43. Abelyan, N.; Grabski, H.; Tiratsuyan, S. Molecular Biology., 2020, 54(1), 134-143. 